\title{
Tracking down on 50-year History of Research about Information Management and Technology in Korea
}

\author{
Dept. of Domestic Information \\ Information Service Center \\ Korea Institute of Science and Technology Information
}

Keywords: Journal of Information Science Theory and practice, Journal of Information Management, JISTaP, Korea Institute of Science and Technology Information, KISTI

\section{INTRODUCTION}

JISTaP(Journal of Information Science Theory and practice) is a newly launched journal focusing on information management and technology, replacing the existing domestic journal, Journal of Information Management which has been published over 50 years now, with a new international one. Journal of Information Management was an intellectual property which comprehensively defined the role of KISTI(Korea Institute of Science and Technology Information) in science and technology such as information production, collection, organization, database building, information dissemination, and standardization.

This paper includes R\&D outputs on information content, cases regarding information services de- signed and implemented by the information professionals of Korea to reflect changes in both scholarly communications and information technologies. Many theories established on library and information science and research outputs collaborated with other fields of studies as well as works of early foreign researchers are the examples of its coverage.

To commemorate the birth of JISTaP, the direction and aim of JISTaP will be set up by providing analytical review of the fifty years of Journal of Information Management. This is also to provide a guiding principle for the readers and contributors in the future.

\section{PUBLICATION STATUS}

\subsection{Publication History}

As Korea Scientific and technological Information

\section{Open Access}

Received date: February 27, 2013

Accepted date: March 24, 2013

*Corresponding Author: Seon Heui Choi

Principal Researcher

Dept. of Domestic Information

Information Service Center, KISTl

Republic of Korea

E-mail: Sunny.choi@kisti.re.kr
All JISTaP content is Open Access, meaning it is accessible online to everyone, without fee and authors' permission. All JISTaP content is published and distributed under the terms of the Creative Commons Attribution License (http://creativecommons.org/licenses/by/3.0/). Under this license, authors reserve the copyright for their content; however, they permit anyone to unrestrictedly use, distribute, and reproduce the content in any medium as far as the original authors and source are cited. For any reuse, redistribution, or reproduction of a work, users must clarify the license terms under which the work was produced. 

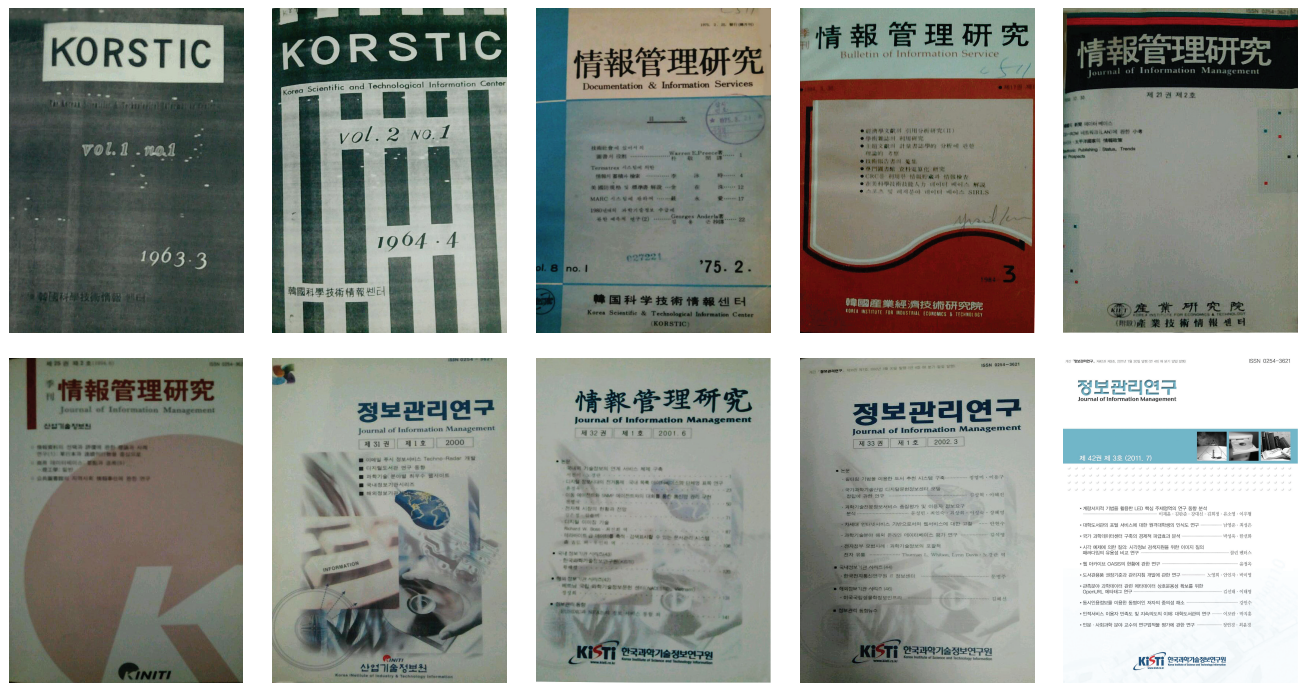

Fig. 1 History of Journal of Information Management's Cover

Center(KORSTIC) was established in 1962, KORSTIC had been published as an bulletin to advertise and publicize the organization in 1963, but discontinued in December 1966 as Volume 3, number 1. In 1971, KORSTIC is retitled Journal of Information Management and served as a professional magazine to propagate information trends and technological diffusion in addition to its previous role as an advertisement of the organization. Journal of Information Management, which were being issued bimonthly, had been temporarily suspended for two years from 1986 to 1987 then reissued in 1988. In 1990s, it provided methodologies through a comprehensive research on theories and practices in the field of information management as well as practical guidelines for information management professionals. As the journal became a quarterly publication, its contents grew more versatile. Along with academic articles, a series of information management institutes analysis was published and external authors increased to vary the topics of submitted articles. As time went by, its groundwork as a journal publication hardened; articles with depth in many fields of studies were submitted and it finally became one of Korea
Research Foundation registered journals. Moreover, Journal of Information Management accomodated to the recent trends by applying the ISO standard process to its publications in 2008. In 2010, it was converted to an open access journal.

The fifty years of Journal of Information Management can be divided into three periods: the first being 1963 to 1970, a publication focusing on the organization's activities. In the second period (1971 $\sim$ 1991), it served to introduce quality academic articles from in and out of the country as well as an academic magazine which introduces various information management organizations. The year 1992 marked the beginning of the third period in which it matured into a professional academic journal.

\subsection{Total Number of Articles}

Since 1963 to 2012, which marked the 50th year of Journal of Information Management, the total number of articles published is 915 . This is approximately 21 articles per year. The number of articles published increased gradually, and the year with the most publications was 2011 (44 articles). The year 2008 with 41 articles, 2012 with 38, and 2010 with 37 
Table 1. Publication history of Journal of Information Management

\begin{tabular}{l|l}
\hline 1963 & Publication of KORSTIC \\
1966 & $\begin{array}{l}\text { Discontinuance of KORSTIC } \\
1971\end{array}$ \\
$1986-87$ & $\begin{array}{l}\text { Pe-issued under the name of Journal of Information Management, a bimonthly } \\
1988\end{array}$ \\
1992 & Re-issuance of Journal of Information Management expanded and distributed as a quarterly journal \\
1996 & Changed to Quarterly Publication \\
2007 & Appoistered at bureau of Public Information's Regular Publication. (Registration No. 12641) \\
2010 & Changed to OpenAccess academic journal \\
\hline
\end{tabular}

articles followed respectively. Note that no articles were published during 1967 1970 and 1986 1987. Table 2 illustrates the per-year publication numbers.

Rearranging the data with a granularity of 5 year periods, the numbers of published articles for the 3rd period(122 articles for 1973 1977) and 4th(103 for 1977 1981) showed drastically increased compared to those of 1st(36) and 2nd five years(41). Total 225 articles published during the 3rd and 4th period amounted to $1 / 4$ of the entire articles(915),

Table 2. Journal of Information Management Per-year Publication Numbers

\begin{tabular}{|c|c|c|}
\hline $\begin{array}{c}\text { Publication } \\
\text { Year }\end{array}$ & $\begin{array}{c}\text { No. of } \\
\text { Publication }\end{array}$ & $\begin{array}{l}5 \text { year } \\
\text { total }\end{array}$ \\
\hline 1963 & 8 & \multirow{5}{*}{36} \\
\hline 1964 & 18 & \\
\hline 1965 & 6 & \\
\hline 1966 & 4 & \\
\hline 1967 & - & \\
\hline 1968 & - & \multirow{5}{*}{41} \\
\hline 1969 & - & \\
\hline 1970 & - & \\
\hline 1971 & 20 & \\
\hline 1972 & 21 & \\
\hline 1973 & 26 & \multirow{5}{*}{122} \\
\hline 1974 & 26 & \\
\hline 1975 & 23 & \\
\hline 1976 & 23 & \\
\hline 1977 & 24 & \\
\hline 1978 & 24 & \\
\hline 1979 & 22 & \\
\hline
\end{tabular}

\begin{tabular}{|c|c|c|}
\hline $\begin{array}{c}\text { Publication } \\
\text { Year }\end{array}$ & $\begin{array}{c}\text { No. of } \\
\text { Publication }\end{array}$ & $\begin{array}{c}5 \text { year } \\
\text { total }\end{array}$ \\
\hline 1980 & 17 & \multirow{3}{*}{103} \\
\hline 1981 & 22 & \\
\hline 1982 & 18 & \\
\hline 1983 & 30 & \multirow{5}{*}{72} \\
\hline 1984 & 25 & \\
\hline 1985 & 17 & \\
\hline 1986 & - & \\
\hline 1987 & - & \\
\hline 1988 & 9 & \multirow{5}{*}{50} \\
\hline 1989 & 10 & \\
\hline 1990 & 8 & \\
\hline 1991 & 7 & \\
\hline 1992 & 16 & \\
\hline 1993 & 15 & \multirow{4}{*}{73} \\
\hline 1994 & 14 & \\
\hline 1995 & 17 & \\
\hline 1996 & 14 & \\
\hline
\end{tabular}

\begin{tabular}{|c|c|c|}
\hline $\begin{array}{c}\text { Publication } \\
\text { Year }\end{array}$ & $\begin{array}{c}\text { No. of } \\
\text { Publication }\end{array}$ & $\begin{array}{c}5 \text { year } \\
\text { total }\end{array}$ \\
\hline 1997 & 13 & \\
\hline 1998 & 13 & \multirow{5}{*}{85} \\
\hline 1999 & 15 & \\
\hline 2000 & 14 & \\
\hline 2001 & 19 & \\
\hline 2002 & 24 & \\
\hline 2003 & 22 & \multirow{5}{*}{140} \\
\hline 2004 & 22 & \\
\hline 2005 & 32 & \\
\hline 2006 & 31 & \\
\hline 2007 & 33 & \\
\hline 2008 & 41 & \multirow{5}{*}{193} \\
\hline 2009 & 33 & \\
\hline 2010 & 37 & \\
\hline 2011 & 44 & \\
\hline 2012 & 38 & \\
\hline \multicolumn{2}{|c|}{ Total } & 915 \\
\hline
\end{tabular}




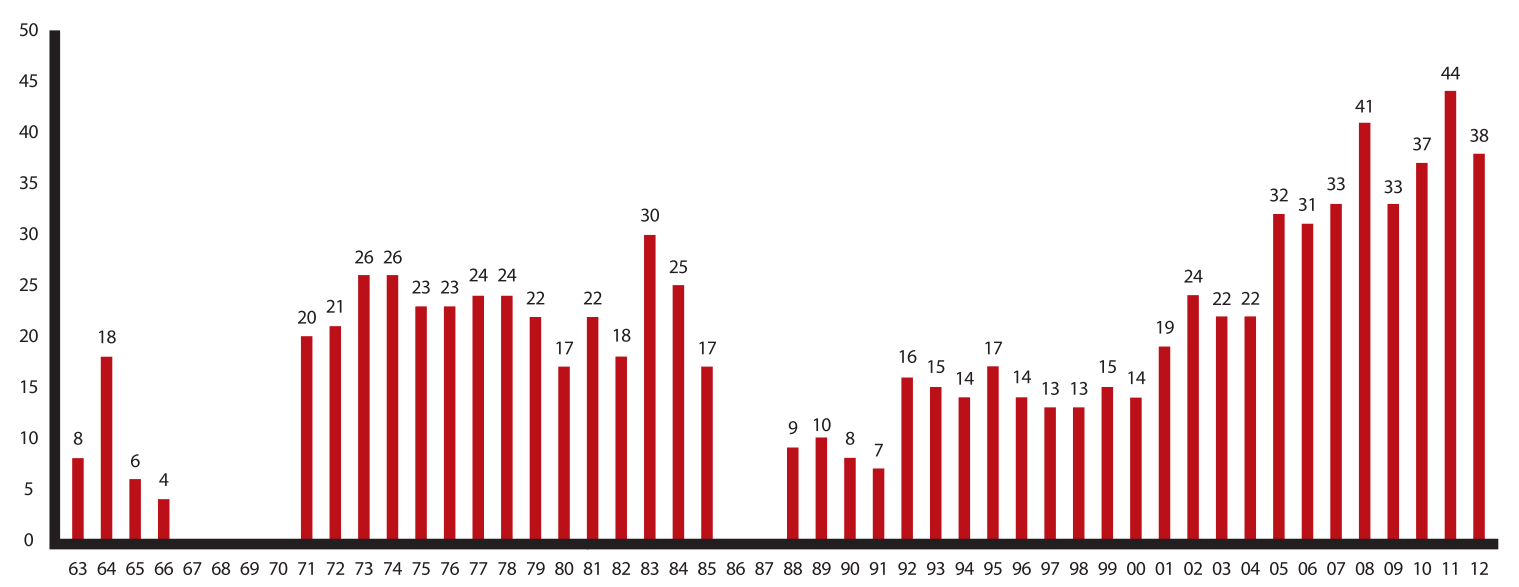

Fig. 2 Journal of Information Management yearly published Numbers

corresponding 22.5 publications per year. The reason that accounts for a bigger volume of publications for these periods was that the journal revived with a new title called Journal of Information Management and a new frequency of 'bi-monthly'. Immediately after this period, the number of articles published seemed to dwindle. However, the trend reversed to have 140 articles for 2003 2007 and 193 for 2008 2012 period. The 2003 2012 period showed the biggest volume of 333 publications to take up $36.4 \%$ of all published articles (33.3 articles per year).

\subsection{Authors}

The total number of authors who contributed to Journal of Information Management is 1,341 and the average number of authors per article came out to be 1.5. Without duplicates, the total number of unique authors were 791. Table 3 . lists the 28 authors who have contributed more than 6 articles. Yoon Hee-Yoon has the most articles contributed. Yoon's first submission was in 2002, and authored a total of 13 articles. The main areas of the author's works were public libraries ( 4 articles), scholarly communication ( 3 articles), and 2 articles for the following areas : foreign journals, copyrights, and science and technology resources. Nam young-joon (12), Choi Sung-Yong (10), and Lee Jae-Yoon(9) followed Yoon as shown in table 3.

Figure 3 shows the per-year article distribution graph of the most contributing authors to Journal of Information Management. It is evident that the ratio of external authors sharply increased from $5.5 \%$ to $65.5 \%$ starting the year 1992 when the journal began to focus on scholarly research. Also, it seemed that the increase of external authors since 2002 had affected the change of keywords.

Comparing the appearance frequency of authors' affiliations by both KISTI and external organizations, KISTI comprised 36\%(433 times) (see Figure 4). This shows that Journal of Information Management was a type of representative bulletin of the organization. The affiliations other than KISTI were universities $42 \%$ (538 times), other research institutes 14\% (170 times), corporate libraries 5\% (62 times), a combination of public and school libraries, newspaper agencies, and academic societies 3\%(39 times). More specifically, the distribution of university showed that Yonsei University had the most appearances (67 times) which is approximately $12.4 \%$. Chung-Ang University had 61 times (11.3\%), Chung-Nam National University 36 times (6.7\%), Ehwa Womans University 34 times (6.3\%). Also, KeiMyung University and Daegu University both had 21 appearances $(3.9 \%$ each). Kyonggi University, Chonbuk University, Chonnam National University, 
Table 3. 28 Top Ranking Authors who have contributed to Journal of Information Management

\begin{tabular}{|c|c|c|c|c|c|}
\hline Author & Affiliation & $\begin{array}{l}\text { No. of } \\
\text { Articles }\end{array}$ & Author & Affiliated & $\begin{array}{c}\text { No. of } \\
\text { Articles }\end{array}$ \\
\hline Yoon, Hee-Yoon & Daegu University & 13 & Hwang, Hye-Kyong & KISTI & 7 \\
\hline Nam, Young-Joon & Chung-Ang University & 12 & Noh, Kyung-Ran & KISTI & 7 \\
\hline Choe, Seong-Yong & KISTI(KORSTIC) & 10 & Seo, Tae-Sul & KISTI & 7 \\
\hline Lee, Jae-Yun & Kyonggi University & 9 & Yu, Gyeong-Hui & KISTI(KORSTIC) & 7 \\
\hline Choi, Hee-Yoon & KISTI & 8 & Kim, Eun-Sik & KISTI(KIET) & 6 \\
\hline Kim, Hye-Sun & KISTI & 8 & Kim, Seong-Hee & Chung-Ang University & 6 \\
\hline Kim, Sung-Won & $\begin{array}{l}\text { Chungnam National } \\
\text { University }\end{array}$ & 8 & Kim, Suk-Young & KISTI & 6 \\
\hline Lee, Eung-Bong & $\begin{array}{l}\text { Chungnam National } \\
\text { University }\end{array}$ & 8 & Lee, Jee-Yeon & Yonsei University & 6 \\
\hline Lee, Hyeon-Cheol & KISTI(KORSTIC) & 8 & Lee, Jeong-Il & KISTI(KORSTIC) & 6 \\
\hline Nam, Tae-Woo & Chung-Ang University & 8 & Lee, U-Beom & Hansung University & 6 \\
\hline Oh, Dong-Geun & Keimyung University & 8 & Mok, Yeon-Gyun & KISTI(KIET) & 6 \\
\hline SaGong, Cheol & KISTI(KORSTIC) & 8 & NamGung, Bong & KISTI(KORSTIC) & 6 \\
\hline Yu, Ja-Gyeong & KISTI(KORSTIC) & 8 & Park, Hyun-Woo & KISTI & 6 \\
\hline Ahn, Hyun-Soo & KT R\&D Group & 7 & Yoon, Cheong-Ok & Cheongju University & 6 \\
\hline
\end{tabular}

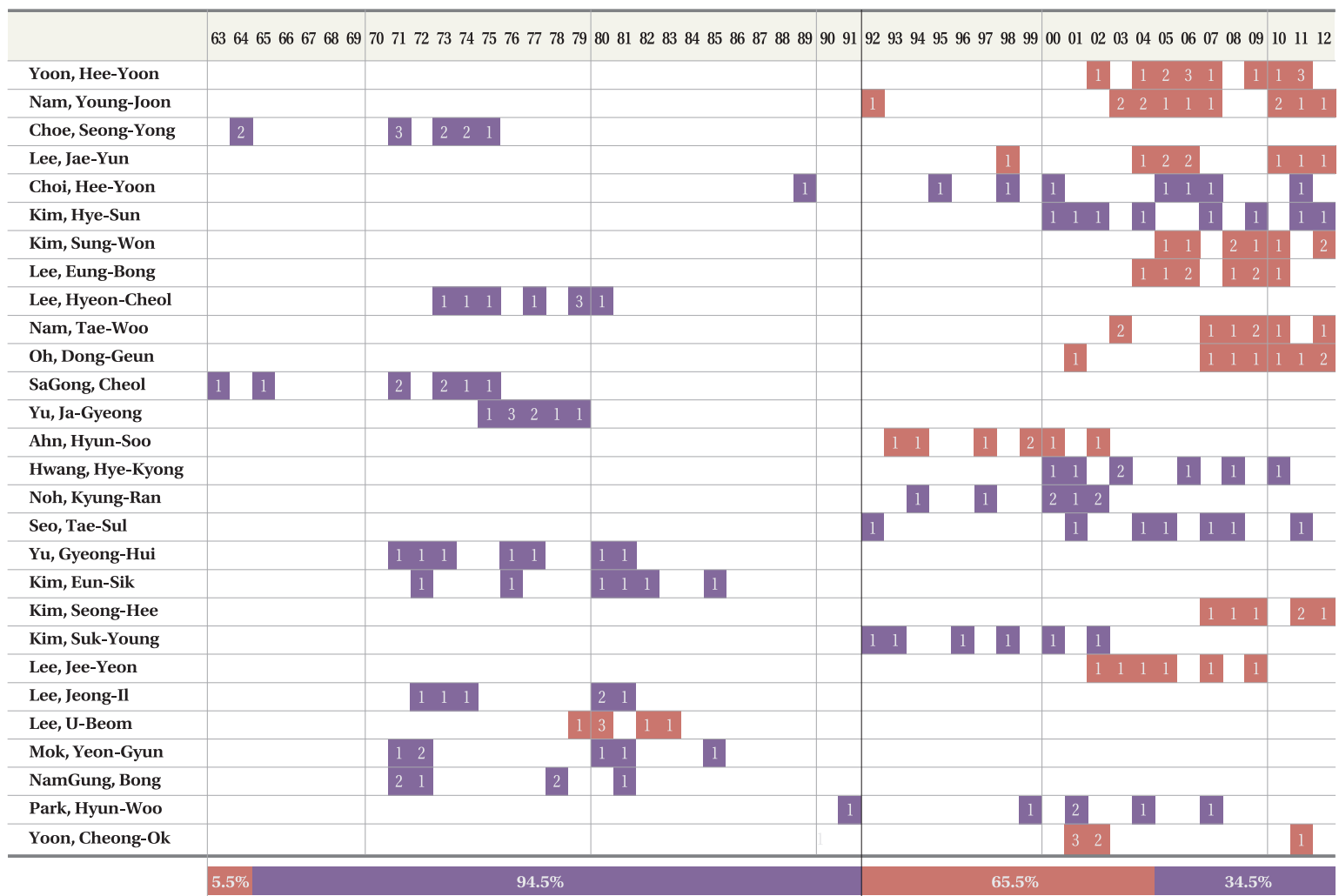

Fig. 3 Yearly Article Distribution of Top Rankin Authors 
Busan University, and Kyungpook National University follwed in the order.

Lastly, a total of 106 foreign authors appeared in Journal of Information Management over the last fifty years, comprising $13 \%$ among the total 791 authors.(see Figure 5). 96 articles out of 102 were identified to be translated articles, and non-translated articles authored by foreign authors had began to be directly submitted since 2007 .

During the time, as the main goal of the journal publication was to propagate overseas technology transfer and trend information, many translated foreign articles were introduced to the domestic readers.

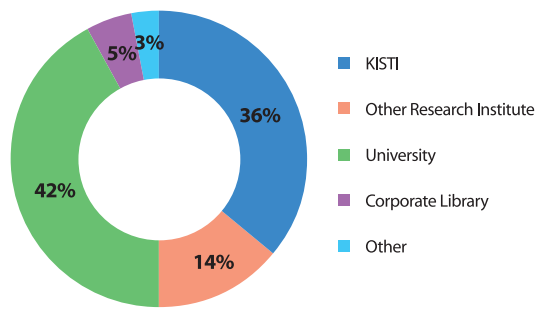

Fig. 4 Ratio of Affiliation of Authors

\subsection{Keywords}

The use of "Keywords" started mainly in 1992, and they were in Korean and English language. Only English keywords were used for this job. A total of 1903 words were identified and this is about 5.4 keywords per articles. The most used keyword reflects the topic of interest of the contributors. Table 4 shows the most used keywords and their count. Among all keywords, "Database" was the most used word with a count of 30. "Digital Library" and "Electronic Journal” followed "Database".

Figure 6 represents the distribution graph based on the keywords from Table 4. We observe that "Database”, "Digital Library”, "Electronic Journal”, “Univer-

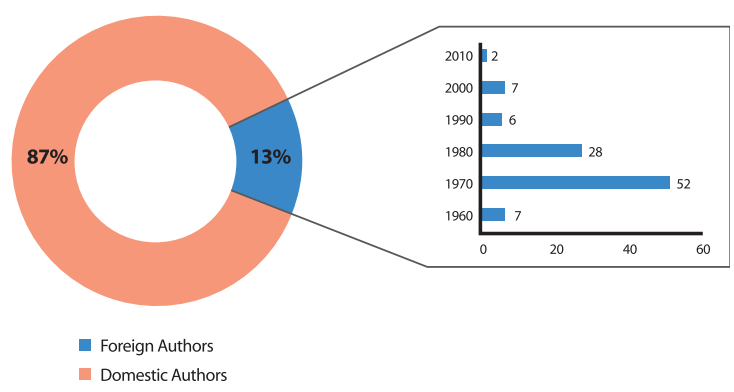

Fig. 5 Foreign Authors in Journal of Information Management

Table 4. Keywords Used the Most

\begin{tabular}{l|l|l|c}
\hline \multicolumn{1}{c|}{ Keyword } & No. of Times & Keyword & No. of Times \\
\hline Database & 30 & Collection Development & 9 \\
Digital Library & 23 & Copyright & 8 \\
Electronic Journal & 16 & Knowledge Management & 8 \\
Information Retrieval & 15 & Scholarly Communication & 8 \\
Internet & 15 & Science and Technology Information & 8 \\
University Library & 15 & Academic Library & 7 \\
Citation Analysis & 14 & KESLI & 7 \\
Metadata & 14 & KISTI & 7 \\
Public Library & 14 & Resource Sharing & 7 \\
Information Service & 13 & Thesaurus & 7 \\
Open Access & 12 & User Satisfaction & 7 \\
\hline
\end{tabular}




\begin{tabular}{|c|c|c|c|c|c|c|c|c|c|c|c|c|c|c|c|c|c|c|c|c|c|}
\hline Keyword & 92 & 93 & 94 & 95 & 96 & 97 & 98 & 99 & 00 & 01 & 02 & 03 & 04 & 05 & 06 & 07 & 08 & 09 & 10 & 11 & 12 \\
\hline Database & 4 & 3 & 3 & 1 & 3 & 3 & 1 & 1 & & 2 & 1 & & & 2 & 2 & & & 2 & 1 & 1 & \\
\hline Digital Library & & & & 2 & 1 & 3 & 1 & 2 & & 1 & & 2 & 1 & & 2 & 2 & 2 & & 1 & 3 & \\
\hline Electronic Journal & 1 & & & 1 & & 2 & & & & 1 & 1 & 1 & 2 & & - & . & 3 & 1 & 2 & 1 & \\
\hline Information Retrieval & 3 & 3 & 1 & 1 & & & & 2 & & & & & & 2 & 1 & 2 & & & & & \\
\hline Internet & & & & 3 & 2 & 2 & 4 & 1 & & & 1 & & & 1 & 1 & & & & & & \\
\hline University Library & & & 1 & 1 & & & 1 & & & & & 2 & 1 & & 1 & 1 & 1 & & 1 & 1 & 1 \\
\hline Citation Analysis & & 3 & & & & 1 & & 1 & & & & & & 2 & & 2 & 2 & & 1 & & 2 \\
\hline Metadata & & & & & & & & 1 & & & & 1 & 1 & 2 & 2 & 1 & 2 & 2 & 1 & & 1 \\
\hline Public Library & & & 1 & & & & & & & & & 1 & & 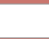 & 1 & 2 & & 1 & 3 & 2 & 3 \\
\hline Information Service & 1 & 1 & & & 1 & 1 & & 1 & & 1 & & 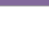 & & 1 & 1 & 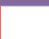 & 2 & & 1 & 1 & 1 \\
\hline Open Access & & & & & & & & & & & & 1 & 1 & 2 & 1 & 1 & 3 & & 1 & 2 & \\
\hline Collection Development & & & & & & & & & & & 1 & 2 & 1 & & & 2 & 3 & & & & \\
\hline Copyright & & & & & & 1 & & & & & 1 & & 1 & 2 & 1 & 3 & & & & & 1 \\
\hline Knowledge Management & & & & & & & & & & & & 1 & & 1 & 2 & & 1 & 1 & 1 & 1 & 1 \\
\hline Scholarly Communication & & & & & & & & & 1 & & 1 & 1 & 1 & 2 & 1 & 2 & & & & 1 & \\
\hline Science and Technology Information & & & & & & & & 1 & & & 1 & & 1 & 2 & 1 & & 1 & & & & 1 \\
\hline Academic Library & & & & & & 1 & & & & & & & & & & 1 & 1 & & & 4 & \\
\hline KESLI & & & & & & & & & & & & & & & 1 & & 2 & 1 & 1 & 1 & 1 \\
\hline KISTI & & & & & & & & & & 5 & 1 & & & & & & & & & & 1 \\
\hline Resource Sharing & & 2 & & & & 1 & & & & 2 & & & & & & & 1 & 1 & & & \\
\hline Thesaurus & 1 & & & & & 1 & 1 & & & 1 & & 1 & & & & 1 & & 1 & & & \\
\hline User Satisfaction & & & & & & & & & & & 1 & & & & & 1 & & & 1 & 4 & \\
\hline
\end{tabular}

Fig. 6 Yearly Distribution of Top Ranking Keywords

sity Library", "Information Service" have been the most frequently appeared topics of interest over the last 20 years (1992 2012). Dividing the keyword usage into two periods of 1992 2001 and 2002 2012, reveals that articles with more varying topics were submitted in the later period than the former. "Metadata", "Public Library," “Open Access", "Collection Development”, "Science and Technology Information", "Scholarly Communication", "Knowledge Management”, "Copyright”, "Academic Library", "KESLI”, “KISTI”, "Resource Sharing”, "Thesaurus", and "User Satisfaction" were the keywords appeared more frequently in the later period. Some of the keywords appeared in the later period such as Public Library, Collection Development, Scholarly Communication, Knowledge Management, Academic Library, User Satisfaction differed from those that frequently appeared in the former period. This phenomena accorded with the period(2002) in which the number of external authors increased as shown in Figure 3.

Table 5 shows the keyword distribution by subdivided time periods. In the first period, "Database" were used 7 times in the 2 year span and 11 times in the next 4 year span ('94 '98). This shows that the researchers in the field had a great interest in that keyword. The most used keywords for each 5-year time periods were identified as Database - Database - KISTI - Metadata - Public Library respectively. Such keywords, which differed in terms of propensity, started appearing in 2004 and had become a mainstream after 2009.

\section{CONCLUSIONS}

This paper investigated changes in both scholarly communications and information technologies in Korea for 50 years by reviewing 915 articles published in the Journal of Information Management from 1963 through 2012. It also analyzed researchers and article keywords published in that journal. The following parts summarize research results of this study.

- From 1963 to its 50th anniversary in 2012, the Journal of Information Management totally published 915 articles, publishing a yearly average of 21 articles(the average excluding the year of which no article has been published). The year with the most articles was 2011 (44 articles). 
Table 5. Keyword Distribution per Section

\begin{tabular}{|c|c|c|c|}
\hline Year & Ranking & Keyword & No. of times \\
\hline \multirow{5}{*}{$1992 \sim 1993$} & 1 & Database & 7 \\
\hline & 2 & Information Retrieval & 6 \\
\hline & 3 & Automatic Indexing & 3 \\
\hline & 4 & Citation Analysis & 3 \\
\hline & 5 & Acquisition System & 2 \\
\hline \multirow{5}{*}{$1994 \sim 1998$} & 1 & Database & 11 \\
\hline & 2 & Internet & 10 \\
\hline & 3 & Digital Library & 7 \\
\hline & 4 & Hypertext & 5 \\
\hline & 5 & SGML & 5 \\
\hline \multirow{5}{*}{ 1999 2003 } & 1 & KISTI & 6 \\
\hline & 2 & Database & 5 \\
\hline & 3 & Digital Library & 5 \\
\hline & 4 & Authority Control & 4 \\
\hline & 5 & Authority File & 3 \\
\hline \multirow{5}{*}{ 2004 2008 } & 1 & Metadata & 8 \\
\hline & 2 & Open Access & 8 \\
\hline & 3 & Digital Library & 7 \\
\hline & 4 & University Library & 7 \\
\hline & 5 & Citation Analysis & 6 \\
\hline \multirow{5}{*}{$2009 \sim 2012$} & 1 & Public Library & 9 \\
\hline & 2 & Scientific Data & 5 \\
\hline & 3 & User Satisfaction & 5 \\
\hline & 4 & Academic Library & 4 \\
\hline & 5 & Digital Library & 4 \\
\hline
\end{tabular}

- The authors who have contributed to Journal of Information Management is 1,341 (overlapping aspect is removed, it indicated 791 authors) in total, and 1.5 author per each article contributed their writing. Hee-Yoon Yoon submitted the most articles, 13 articles, as a main author.

- In particular, since the year of 2002, it can be noted that the ratio of external authors rapidly increased, and such rapid increase of external authors seemed to have affected the change of keyword.

- Ratio of affiliation of authors were KISTI affiliated authors comprised 36\% (433 times), universities took up $42 \%$ (538 times), research center other than KISTI took up 14\% (170 times), corporate reference room took up 5\% (62 times), regional library, elementary, middle and high school library, newspapers, academy and so on took up 3\% (39 times). If a closer look is taken on universities which had shown the most proportion, Yonsei University accounted for $12.4 \%$ of the total with 67 times.

- Foreign authors appearing in Journal of Information Management, a total of 106 authors were 
involved in the past. Out of 102 articles of foreign authors, 96 articles appeared as translated items, and from 2007, articles which were not translated were contributed

- From 1992, the keyword in Journal of Information Management began to be used in earnest. The keywords were a total number of 1,903, and the average keyword per each article showed to be 5.4. Among all keywords, "Database" was the most used word.

- The introduction of keywords in the second half was somewhat different from the previous themes, and this corresponds to the period of increased foreign authors since 2002.

The Journal of Information Management was published for many years in library and information science in Korea. Once its publication had ceased, but the journal was reissued as a better journal. JISTaP will develop based on the Journal of Information Management.

\section{Reference}

Choi, H. K. (1999). An analytical study on research patterns in library and information science. Journal of the Korean Society for information Management, 16(3), 137-158.

Oh, S. H., \& Lee, T. Y. (2005) Research trends of information science in Korea. Journal of the Korean Society for information Management, 22(1), 167189.

Sohn. J. P. (2003). An analytical study on research trends of library and information science in Korea : 1957 2002. Journal of Korean Library and Information Science Society, 34(3), 9-32.

Korea Institute of Science and Technology Information (2012). The 50th year of KISTI. Daejeon: Korea Institute of Science and Technology Information. 